\title{
Lecturas adultas y lecturas infantiles. El universo de Kitty Crowther en la formación del mediador como lector literario
}

Adult lectures and childlike lectures. The universe of Kitty Crowther in the formation of the literary reading mediator

\author{
Dra. Rosa Tabernero Sala \\ Departamento de Didáctica de las Lenguas \\ y de las Ciencias Humanas y Sociales. \\ Universidad de Zaragoza. \\ rostab@unizar.es
}

\section{Resumen}

Varias son las investigaciones que se han centrado en reflexionar sobre la figura el mediador escolar y en la importancia de este último en la formación del lector literario. En este marco, los resultados generados por una investigación de corte cualitativo llevada a cabo en el ámbito de la Comunidad Autónoma de Aragón en colaboración con el Grupo ELLIJ de la Universidad de Zaragoza han incidido en la diferencia que existe entre las lecturas adultas y las lecturas infantiles. Así, por ejemplo, el lector adulto en su faceta de mediador rechaza los temas tradicionalmente considerados difíciles en cualquier propuesta de lectura infantil. Sin embargo, el lector infantil se acerca a estos temas con especial interés. Una de las autoras que mejor representa esta diferencia de recepción es Kitty Crowther. El presente artículo profundiza en una propuesta de lectura de la obra de esta autora partiendo de la necesidad de redefinir el concepto de lector infantil desde la perspectiva del mediador.

\begin{abstract}
There are a lot of investigations which are focused in thinking about literary reading mediator in school settings and his importance in literary reader's formation. Here, the results generated by qualitative investigation, carried out by Comunidad Autónoma de Aragón collaborating with ELLIJ Group, from Zaragoza's University; deepen in the difference between adults lecture and the children one. For instance, adult reader in his mediator scope refuses issues that have been always considered taboos in any child's reading proposal. Nevertheless, childlike reader approaches to these issues with a special interest. One of the authors that best represents this different perception is Kitty Crowther. This article deepens in a lecture proposal of her work, starting from the necessity of redefining the childlike reader's concept from a mediator scope.
\end{abstract}

Palabras clave: Lector literario, Lectura adulta, Lectura infantil, Temas difíciles, Álbum, Libro ilustrado, Kitty Crowther.

Keywords: Literary reader, Adult lecture, Childlike lecture, Taboo, Album, Picturebook, Kitty Crowther 


\section{Introducción}

Pedro Salinas (2002, p. 176) resumía el sentido de la lectura literaria en la idea de que aprender a andar por el mundo imaginario enseña a caminar por el mundo real. La lectura literaria implica por parte del lector, por tanto, un desarrollo de la capacidad de aprender a interpretar y a valorar las creaciones de carácter estético-literario (Mendoza, 2004, p. 15). Resulta necesario, además, desvincular la lectura literaria de las herramientas propias de la comprensión lectora dirigida al acceso y a la transferencia del conocimiento e insistir en la relación entre lectura literaria y construcción de identidad de tal modo que el discurso literario, la literatura, ayuda a explicar el mundo que rodea al individuo y las relaciones humanas en un contexto social y, por tanto, cultural, en un ejercicio magistral de formación de ciudadanos (Bruner 1988; Rosenblatt, 2002):

El contacto prolongado con la literatura puede provocar una mayor sensibilidad social. A través de cuentos, poemas y obras de teatro el niño va cobrando conciencia de las personalidades de diferentes tipos de gente. Aprende a ponerse imaginativamente en el "lugar del otro". (...) (Rosenblatt, 2002, p. 207).

Guiados por estas apreciaciones, varios son los estudios que han versado sobre la figura del mediador y de su formación en este ámbito. Por una parte, los estudiantes universitarios, según muestran los estudios de Larrañaga, Yubero y Cerrillo (2008) no leen $(40 \%)$ y el $16 \%$ se declara lector ocasional. Por otra parte, Granado Alonso (2009) centra su investigación en los estudiantes de Magisterio y obtiene resultados dignos de consideración: solo el 36\% se declara lector y el $70 \%$ expone reticencias claras ante la educación literaria recibida. Si, como bien señalaba A. Chambers (2007), es difícil que los mediadores transmitan experiencias no vividas, no es extraño llamar la atención sobre el hecho de que difícilmente se podrá inculcar un hábito lector cuando la persona que lo debe transmitir no es lectora.

En el marco de estudios como los de Silva-Díaz (2001), Duszinsky, 2006, Díaz Armas, (2008), Munita $(2013,2014)$, Dueñas et al (2014) se constata que el maestro o futuro maestro posee una serie de prejuicios acerca de la literatura infantil que, de algún modo, las propuestas de investigación y formativas deben paliar. Así, por ejemplo, la inclinación por el realismo en detrimento de la fantasía, la priorización de ilustraciones con colores llamativos y bien perfiladas sobre estilos que requieren una mayor competencia artística por parte del receptor, el léxico no habitual o la necesidad de vincular la literatura a la enseñanza de valores se exponen como creencias fundamentales del adulto ante el discurso literario infantil en virtud del receptor al que se dirige y al que el maestro en formación le confiere desde la hipótesis una serie de capacidades, en ocasiones, no demasiado adecuadas a la realidad del destinatario. Para los futuros mediadores, la literatura infantil se compone de un corpus de análisis de lectura fácil y no demasiado comprometida. Por esta razón, estudiosos como T. Colomer (2009, 2010), G. Lluch y J. Chaparro (2007), G. Lluch (2010) o J. Díaz Armas (2008), entre otros, han ofrecido diferentes propuestas de análisis de textos que intentan paliar esos vacíos que hemos mencionado anteriormente. 
Por nuestra parte, con este objeto, desde el año 2012, hemos realizado en el marco de la Comarca de Somontano ${ }^{5}$ (Comunidad autónoma de Aragón) varias investigaciones de corte cualitativo que han generado propuestas y resultados expuestos en diferentes artículos (Tabernero, 2013, 2014, 2015). El proyecto presentado, de cuatro años de duración, se basa en el trabajo, dentro del marco de Educación Infantil y Primer ciclo de Educación Primaria, con maestros, bibliotecarios, familias y especialistas y en la recogida de datos a través de técnicas e instrumentos como la observación y grabación de las sesiones de lectura de maestras y alumnos, entrevistas semiestructuradas con maestras, bibliotecarias, familias, diarios de campo de maestras y bibliotecarias y grupos de discusión con maestras y bibliotecarias.

En el último curso, hemos llevado a cabo una propuesta centrada solo en Educación Infantil.

Uno de los resultados que hemos obtenido en la última fase de nuestra investigación tiene que ver con la diferencia que existe entre las formas de leer de los adultos y la forma de leer de los niños. Existen diferencias pronunciadas entre la lectura adulta y la lectura infantil de un mismo libro. Desde los presupuestos de partida entendimos que posiblemente existía una diferencia pronunciada entre la recepción de una misma obra por parte del adulto mediador y del niño, todo ello vinculado, por supuesto, a los prejuicios con los que el adulto se aproxima a la literatura infantil. En los diferentes grupos de discusión que mantuvimos tres de la obras más cuestionadas fueron, por poner un ejemplo, El pato y la muerte de W. Erlbruch, Theo y Dios de K. Crowther La cocina de noche de M. Sendak. Las dos primeras por tratar temas que no se consideraban adecuados a la infancia y la tercera por presentar un sentido del humor que no creían entender. Sin embargo, las tres obras fueron las más solicitadas por los niños y las que suscitaron tanto una lectura pública como después privada.

Sin duda, uno de los prejuicios que late en la selección que los adultos realizan de obras infantiles tiene que ver con la presencia de temas difíciles que, en su opinión, conviene no tratar con los niños. A este prejuicio se le une la diferencia de lecturas entre adulto y niño de tal modo que consideramos necesario profundizar en los grupos de discusión con maestras sobre la propuesta de los diferentes autores que fueron no demasiado apreciados por el adulto y, sin embargo, consiguieron el favor del alumno de Educación Infantil. Una de las primeras autoras con las que se trabajó fue Kitty Crowther por considerar que su tratamiento de los temas tabú era uno de los motivos que alejaba al lector adulto del lector infantil. El análisis de su obra y, por ende, del lector que defiende no deja de ser un modo de incidir en la necesidad de destruir los prejuicios con los que el adulto se acerca a las obras infantiles. La segunda parte de este trabajo versa sobre la mencionada autora con el fin de reflexionar sobre un universo que propone un lector infantil digno de consideración por parte del mediador. Entendemos, de este modo, que una de las carencias que arroja nuestra investigación, en la línea de las ya mencionadas, es la falta de reflexión crítica sobre las obras infantiles y sus respectivos autores. A este objetivo responde lo que a continuación se expone.

\footnotetext{
${ }^{5}$ Las propuestas llevadas a cabo durante estos años se recogen en el blog https://elreyrojo.wordpress.com. Se trata fundamentalmente de dos proyectos: ¿De qué sirve un libro sin dibujos ni diálogos? Álbum y formación de lectores y Lo que leen los niños y los adultos deberían conocer.
} 


\section{La propuesta de Kitty Crowther}

Kitty Crowther es una de las autoras que, a nuestro entender, ha conseguido en los últimos años crear un universo propio en el que los temas tradicionalmente considerados difíciles o inadecuados para el lector infantil surgen de una manera natural, emergen de la propia concepción del lector que la autora, a través de su experiencia de vida, incorpora como estrategia textual. El álbum, por otra parte, es la propuesta gráfica en la que el universo de Kitty Crowther adquiere su sentido extremo. Nos centraremos en el análisis de las bases que sustentan su obra con la incorporación, en algunos momentos, de aportaciones procedentes de la investigación que hemos referenciado más arriba sobre las respuestas de los lectores, en la línea de estudios anteriores como los de Styles \& Arizpe, (2004), Sipe (2000, 2010) o Salisbury \& Styles (2012), entre otros.

\section{a) Kitty Crowther y su universo gráfico}

No son demasiadas las fuentes bibliográficas que pueden ser consultadas para recabar información sobre Kitty Crowther (Bruselas, 1970). Quizá, y esto es algo que ocurre con muchos de los autores modernos, el mayor número de detalles acerca de esta autora se desprenda de las entrevistas que ha concedido que forman parte asimismo del epitexto virtual del propio discurso (Genette, 1987). De los numerosos premios recibidos por Kitty Crowther, el más destacable es el Premio en Memoria de Astrid Lindgren 2010 (Astrid Lindgren Memorial Award), el galardón más importante concedido a un autor de literatura infantil. El jurado destacó de ella lo siguiente:

Kitty Crowther es una maestra de la línea y también del ambiente. Protege la tradición del libro infantil transformándola y renovándola. En su mundo, la puerta entre la imaginación y la realidad está abierta de par en par. Se dirige al lector con un tono amable y personal que logra un fuerte efecto. Su profunda empatía con la gente en una situación difícil, muestra un camino donde la fragilidad puede convertirse en fuerza. El humanismo y la compasión impregnan y unen su obra (Cit.en Los cuatro azules).

Si bien es verdad, todo lo que hemos afirmado hasta ahora, no podemos obviar el hecho de que los últimos tratados sobre álbum recogen su obra gráfica para ubicarla en un lugar de honor. Así Van der Linden (2006, p. 35, 2013, p. 40) destaca de ella las variaciones que realiza sobre la textura del trazo ya que, con la densidad del color, construye efectos sutiles que afloran en los fondos blancos o en efectos cromáticos sostenidos con la utilización del negro en contraste. Además propone su obra como ejemplo de la utilización de técnicas de lápices de colores a la manera de Burningham. Por otra parte, se detiene en la delicadeza y fuerza expresiva de los personajes que, a pesar de ser gráciles, muestran su firmeza. Se fija asimismo en obras como ¿Entonces? para ensalzar la construcción del texto en una combinación paradigmática en lo que a relación texto e imagen se refiere (Van der Linden, 2013a, pp. 68-69 y p. 85). M. Salisbury $(2005,2012,2014)$ ensalza su técnica tradicional y su intimismo en la creación de historias y dentro de las 100 joyas de la literatura infantil ilustrada (2014) cuenta con el trabajo de Kitty Crowther en la ilustración de El gnomo no duerme de Astrid Lindgren, como ejemplo de lo que implica ilustrar el silencio. 
A pesar de que son varios son los aspectos que nos pueden interesar de la autora propuesta, nos vamos a centrar en esta aportación en lo concerniente a la presencia natural, no forzada, de lo que hemos denominado temas difíciles. La obra de Kitty Crowther constituye un universo en sí misma con características que la definen como un mundo con sus propias constantes. Dentro de estas constantes, la peculiar perspectiva con la que se tratan los temas más complejos forma parte de la concepción de un lector modelo que explica la propia autora en muchas de sus intervenciones.

La obra de Kitty Crowther se mueve entre la tradición francófona y la anglosajona de tal modo que combina la línea narrativa anglosajona con el intimismo propio de los autores franceses. Bebe, en este sentido, de autores como Burninghan, Milne, Ungerer, Brunhoff, Lobel, Tove Janson, A. Lindgren, B. Potter, Hergé o Wolf Erlbruch, autores a los que menciona incluso en sus dedicatorias o en sus frases preliminares. Así ocurre en Mère Méduse, en la portadilla en la que aparece la siguiente frase: "Une méduse c'est un corps transparent avec un coeur de fleur. Tove Jansson”.

Sus palabras, por otra parte, nos ayudan a entender las claves desde las que se entiende su obra, claves de creación, en algunos casos, y vitales, en otros momentos.

C. Bessi (2010, p. 139) pregunta a la autora por sus preferencias en lo que a literatura se refiere:

Quelle littérature aimez-vous ?

J'aime la littérature résistante qui donne à réfléchir, qui n'a pas froid aux yeux, avec des livres complets, où se retrouvent la joie et la tristesse. Mon langage à moi, ce sont les enfants car ils m'intéressent profondément. J'aime leur ouvrir les portes, les fenêtres, les emmener dans un autre monde.

Del mismo modo, responde a G. Mirandola (2010, p. 9) cuando esta última le pregunta por la influencia del lector infantil en su concepción de la obra:

Il est rare que je pense aux lecteurs. Je pensé surtout à l'enfant que j'étais. Elle me guide dans mes choix. J'essaie d'être la plus honnête posible vis-à-vis d'elle et vis-à-vis de moi, puisque je ne suis plus cette petite fille.

Especialmente aclaradora resulta la entrevista concedida a Abril Posas (2010) para comprender cómo aborda Kitty Crowther su proceso de creación desde su propia experiencia vital:

Cuando escribo, dibujo, y cuando dibujo siento que escribo. La lectura es un proceso de comunicación, al que se le encuentra un placer. Tengo problemas de oído, no hablé hasta los cuatro años, y me recomendaban mucho leer, por eso creo en el mundo de la cultura. Siempre hemos inventado historias, para entender la vida, la muerte, a nosotros mismos. Por eso me gusta tanto la magia, porque es una forma de pensar, que mezcla el espíritu con la razón.

Se trata del poder de la creación para entender la vida, para poder explicarse. Desde su propia carencia, Kitty Crowther explica la necesidad de abrirse al mundo tal como ella lo traslada a su manera de entender cómo el discurso se construye entra palabra e imagen como formas de comunicación indistintas al servicio del sentido último. Cuando 
se le pregunta en la misma entrevista por su concepción de la literatura en relación con el lector, responde:

Hago textos e ilustración. Siempre intento acercarme a lo que siento y nunca ilustro algo que no me gusta. Sería como traicionarme. No me gustan los libros que adoctrinan. Cuando leo un texto que no es mío, me llegan las imágenes al reconocer las palabras. Quizá porque leo mucho, te das cuenta si es una historia verdadera o algo mecánico. Cuando apartas a un niño de las historias, es una cosa muy triste. Tienes que ser honesto. Los niños no son tan asustadizos. No ven las mismas cosas que nosotros, por eso no temen a lo mismo. Abril Posas (2010).

Kitty Crowther habla de honestidad en la relación entre autor y lector infantil, de contar la vida tal y como es. En este sentido, no es difícil recordar las palabras del gran maestro del álbum, Maurice Sendak. Así explicaba Sendak su sentir acerca de temas inadecuados a W. Lorraine (2012):

El artista pone elementos en su obra que vienen de lo más profundo de sí mismo. Los toma de una vena peculiar de su infancia, siempre abierta y viva. Este es un don especial. Él comprende que los niños saben más de lo que la gente supone. Los niños están dispuestos a enfrentarse con temas dudosos que los adultos quisieran que no conocieran. (...) Todo lo que tratamos de hacer seriamente es hablarles acerca de la vida ¿Qué hay de malo en esto? Y, de todas maneras, ya saben de la vida. (...)

El elemento básico es la honestidad. Sobre cualquier texto que se trabaje, sea realista, fantástico o de ciencia ficción, debe comenzarse con una base de honestidad. Se debe decir la verdad al niño acerca del tema tanto como sea posible, sin mitigar esta verdad. Hay que reconocer que los niños son personas pequeñas y valientes que se enfrentan cada día a una multitud de problemas, tal como los adultos; que no están preparados para muchas cosas y que la mayoría anhela encontrar un poco de verdad en alguna parte. Si este es el punto de partida, después puede procederse en la forma que se desee y echar el cuento de la manera que se quiera. Si es una amarga píldora que los niños no quieren tragar hay que darles la oportunidad de decir no. No se puede ser guardián de los niños ni decidir lo que los niños podrán o no leer.

Desde esta concepción de lector infantil y del álbum como discurso o forma comunicarse con el lector infantil, tan similar a la de Sendak, vamos a analizar la presencia de los temas difíciles, puesto que, tal como señala Ana Zugasti (2014), el tono personal de Kitty Crowther le permite tratar temas inhabituales en la literatura infantil desde la empatía que "logra con el lector, un camino donde la fragilidad puede convertirse en fuerza".

\section{b) El universo de Kitty Crowther desde la perspectiva temática.}

Todas las obras de Kitty Crowther establecen una empatía con el lector desde la honestidad y el respeto absoluto por un receptor que agradece el diálogo al mismo nivel, sin falsos proteccionismos que falsean el discurso. No en vano la propia autora toma el álbum como un lugar de encuentro entre el niño y el adulto, puesto que, a partir de él dos personas pueden hablar, mirar, escuchar y cada uno construye su visión (2013).

Así en la entrevista ofrecida al Astrid Lindgren Memorial Award (ALMA) en 2010, resume las claves desde la que se entiende su obra en una suerte de complicidad con un lector al que se dirige no porque sea infantil sino porque su manera de escribir y dibujar es su "lengua personal", tal como ella misma la define: 
Quality, I would say, is commitment, total sincerity. Honesty. I do not write or draw for children; I write and draw the way I do because it is my personal language. No question that I am deeply interested by children. I love their freshness, their spontaneity, their humour, their displays of wisdom. They are much more real than the many people who hide behind so many filters that they have forgotten who they are. They go through the Moulinex blender of society without noticing it. And it is not necessarily the fault of society (which usually gets the blame for everything). Is it the job of artists to wake them up? (s. f., A book that changed my life).

Sin duda esa "lengua personal" a la que se refiere la autora se refleja en cada una de las obras que expondremos a continuación. Hemos seleccionado aquellas que consideramos representativas del aspecto que nos ocupa y solo destacaremos de ellas los detalles que se centran en los temas y en la forma en la que se presentan en el discurso.

\section{- Moi et rien}

Moi et rien es una historia en la que el eje central es la soledad y la incomunicación, esta vez entre un padre y una hija destrozados por la muerte de la madre. El ritmo de narración ágil con personajes cortados que se suspenden sobre un fondo blanco sin márgenes, a la manera de Babar (Van der Linden, 2008, p. 20), acentúan las sensaciones de tristeza y soledad, todo ello representado por el componente metafórico de la vestimenta de la protagonista que es una americana de su padre, en la necesidad de sentirlo cerca.

\section{- La visite de Petite Mort}

Del mismo modo, en La visite de petite mort, esta vez en un ritmo de narración más pausado, agilizado en el momento en que Petite Mort y Elsewise se hacen amigas, se trata el tema de la muerte, la soledad y, sorprendentemente, del dolor.

Elsewise parle alors de sa maladie et de la douleur qui ne la quittait jamais. Maintenant, elle n'a plus mal. Elle est bien. Petite Mort la regarde, fascinée par son beau sourire (La visite de Petite Mort, p. 19).

Vuelven a aparecer los fondos blancos que subrayan la sensación de frío que sugiere la muerte, sensación acusada por la estética de las máscaras inuits en las que se inspira la autora. Es destacable cómo esta obra en las aulas suscita proyecciones personales (Sipe, 2010) en la medida en que los receptores mencionaban tanto sus preferencias como la necesidad del entorno: "Nos ha gustado el infierno. Mi padre me habla de él". Temas, por lo tanto, familiares, propios del entorno de la infancia que necesitan respuestas. Esta vez es una niña la que acompaña a Petite Mort.

\section{- Dans moi}

Asimismo en Dans moi, representa en escena el imaginario infantil de una manera extremadamente personal, a través de un enfado sordo, de una revuelta silenciosa con una violencia largamente retenida. La ilustración del silencio a través de la paradoja insertada nuevamente en fondos blancos. Tanto L. Cheilan (2010) como G. Mirandola (2010) han reparado en esta personal visión de K. Crowther y en su interés por el cuerpo 
en una suerte de esquizofrenia interior que parece ver la luz. Qué cerca está el Max de Donde viven los monstruos, ese lado oscuro del ser humano también presente en la infancia.

\section{- Theo y Dios}

Tema más complicado que el de Dios en la infancia es difícil de contemplar. Una vez más los fondos blancos que acogen las composiciones en las que el color, el trazo y la luz son los elementos fundamentales en la recreación de un mundo en el que el diálogo entre Theo y Dios se produce entre pinceladas humorísticas. Destacamos en las respuestas lectoras habidas en un grupo de Tercero de Infantil, ésta que se presenta a continuación: "Yo me he dado cuenta de que aunque dios no esté naranja en el libro en todas las páginas hay algo que está en naranja". (Diego. 5 años) ${ }^{6}$

\section{- iScric scrac bibib blub!}

Relacionado con el tema de la soledad, está ;Scric scrac bibib blub!, álbum que versa sobre el miedo a la soledad y la noche y sobre las relaciones entre adultos y niños. Se trata de una historia de ranas en la que el protagonista es Jerónimo que, "como cada noche, tiene miedo". En esta obra, el leguaje, el humor y los contrastes entre luces y sombras, son los protagonistas en la transmisión de sentimientos encontrados como el miedo, la soledad y la relación, en ocasiones paradójica ante los ojos de la infancia, entre padres e hijos. Los marcos en los que la ilustración se encierra protegen a Jerónimo de las pesadillas más oscuras. Todo está controlado y la vida no es otra historia que dominar nuestros miedos.

- ¿Entonces?

¿Entonces? Es una de las obras en la que la teatralidad, tan presente en el universo de Kitty Crowther como procedimiento discursivo, adquiere su máxima dimensión al servicio de la recreación de un ambiente. Elementos como el suspense, la tensión, el paso de página, la elipsis sustentan la complicidad con el lector, en un final que supone un homenaje a la ternura en su estado más puro. Los guiños dedicados al receptor que se definen en una ruptura constante de los niveles del discurso, en un claro procedimiento metadiegético, convierten esta obra dedicada a los más pequeños en un relato complejo en su factura con los juguetes de un niño como protagonistas que esperan la llegada de su dueño. Aclarador en este sentido es el espléndido análisis que realiza de la obra Anne- Sophie Thiry (2006).

\section{- Poka y Mina}

Sophie Van der Linden (2013b, p. 21) habla de los libros correspondientes a Poka \& Mina como correspondientes a lo que se ha dado en llamar Animal Fantasy en la tradición de Grahame y Milne (Winny de Puh) o de Arnold Lobel o de la propia Beatrix

\footnotetext{
${ }^{6}$ Nos referimos a una investigación de Trabajo Fin de Máster que se está llevando a cabo en las aulas de Educación Infantil del Colegio Santa Rosa de Huesca sobre las respuestas lectoras de los niños ante obras tildadas de "difíciles" en lo que respecta al tema tratado y su relación con la infancia.
} 
Potter. Se trata de una comedia de sentimientos en la que los protagonistas, dos insectos al parecer, se explican a través de escenas cotidianas en las que la anécdota esconde lo trascendente. Los personajes aparentemente frágiles colocan los sentimientos en el centro de cada una de las historias desarrolladas en la naturaleza como paisaje y teñidas de humor, sensibilidad y delicadeza. Se establece de nuevo una complicidad con el lector desde diferentes planos discursivos y desde los fondos blancos en los que todo transcurre con ritmo pausado, leve, subrayado por la técnica utilizada en la que destaca la sutileza en el trazo, que implica por parte del lector una lectura íntima, silenciosa, poco proclive, desde la concepción del formato, a ser compartida en el círculo social. Así lo atestiguaron las respuestas lectoras de Tercero de Infantil cuando necesitaban hojear el libro en soledad dentro del espacio del aula.

Van der Linden (2013b, p. 21) subraya en estas obras la ascendencia anglosajona de la "microsociedad" que crea Crowther cuando realiza una síntesis entre lo íntimo y la construcción de mundos imaginarios a la manera de los autores victorianos. Además, señala la proximidad a Badescu en los planteamientos gráficos.

El mundo de Poka y Mina forma parte de esa galería de personajes animales a los que es muy proclive la literatura infantil, tal como señala Nikolajeva (2014, pp. 218-222). Se trata de personajes estáticos aunque complejos en sus acciones. Los diálogos construyen un discurso de varios niveles de complejidad en los que adulto y niño pueden encontrar su propia lectura. Así, por ejemplo en Poka \&Mina. El fútbol, la ironía provoca que, de una forma sutil, se traten temas como el sexismo, la amistad, la competitividad, colectividad/indiviualidad, etc. Todo ello en el marco de una intranscendente historia en la que Mina propone a Poka su deseo de jugar al fútbol... Escasas intervenciones del narrador, diálogos concisos y ágiles y los protagonistas moviéndose aquí y allá en el escenario de las páginas del cada uno de los libros de bolsillo, esta vez.

\section{- Mon ami Jim}

Dentro de esa galería de personajes animales, y en la línea de narración gráfica del autor de Babar, Mon ami Jim trata en una sencilla y metafórica historia el tema de la diferencia y la diversidad, a través de los contrastes gráficos y verbales que se establecen entre sus personajes principales, una gaviota y un cuervo. Mon ami Jim supone, además, un homenaje a los contadores.

\section{- El niño raíz}

Esta obra acaba de ser publicada en España por la editorial Lóguez. Una vez más sobre un telón fantástico se propone el tema de la incomunicación y las relaciones con los otros.

\section{- Mère Méduse}

Mère Méduse es uno de las obras que no puede faltar en esta selección puesto que desarrolla un tema tan complicado como la relación posesiva entre madre e hija, simbolizada por una Madre Medusa que protege a Irisée en la maraña de sus cabellos. Escenas como la asistencia a un parto aparecen en este álbum que bebe en las fuentes de 
la mitología. Aclarador en este sentido, resulta cómo Kitty Crowther explica el proceso de gestación de esta obra en Picturebook Makers (2015). Entre otras ideas, expone en este espacio la autora cómo se inspiró para la construcción de la historia en la observación de experiencias vividas en la realidad en el entorno de cárceles de mujeres y cómo el personaje de Mère Méduse se fue imponiendo a otros por sí mismo, en sus dibujos diarios.

\section{Conclusiones}

Tras el análisis temático de las obras presentadas, entendemos que el universo creado por Kitty Crowther, posee, entre sus claves de concepción, una que nos interesa especialmente: la presencia de temas que tradicionalmente han sido considerados difíciles en la literatura infantil. Estos temas, sin embargo, surgen de las propias historias y de la forma de entender el proceso creativo tanto desde la emisión como desde la recepción. La empatía con la que la autora presenta temas como la muerte, la soledad, el sexismo, las relaciones filiales, la violencia, etc., tal como hemos reseñado, incide en la idea de la concepción del álbum como espacio de encuentro entre un emisor que busca sus historias entre sus propias emociones y habla con el lector desde la honestidad que le sugiere la necesidad de tratar sobre la vida con sus luces y sus sombras, con sus propias contradicciones, con su lado más oscuro, en una concepción del discurso literario infantil muy similar a la de Maurice Sendak. Sin embargo, a diferencia de este último, Crowther transita por la senda abierta por aquel y crea sus propio universo a medio camino entre la necesidad de contar con la realidad y explicarla a través de mundos fantásticos que obedecen a sus propias leyes y que ubican los sentimientos, por complejos que estos sean, en el eje central de cualquier discurso. Su modo de contar, su "lengua personal", está relacionada, por una parte, con su propia experiencia vital como lectora en el silencio que la acompaña desde su infancia, y, por otra, con su concepción del libro como espacio, teatral las más de las veces, en el que explicarse a través de palabras e imágenes que sostienen a los protagonistas en fondos blancos, sobre formatos que acompañan el relato, teñido de un amable humor muy próximo a la ironía que invita a participar asimismo al adulto.

Solo así, podemos acompañar en sus relatos a los protagonistas de Moi et rien, Dans moi, Mon ami Jim, Poka y Mina, El niño Raíz, Scric, entre otras obras. Crowther entiende como nadie la poética del silencio y se muestra especialmente cuidadosa en la construcción de ambientes en los que cualquier tema puede tratarse. Como muy bien expresa Ana Zugasti (2014), "en sus libros siempre se habla de las cosas esenciales de la vida, sean estas grandes o pequeñas".

En definitiva, se trata de una nueva forma de aproximación al álbum, que hunde sus raíces en un profundo conocimiento del género y de sus maestros, que desemboca en una nueva propuesta dentro de la literatura infantil, en una suerte de reinvención de esta literatura y de su lector. Las palabras de la propia autora resultan esclarecedoras:

I like books that demand something of the reader, where things are not glaringly obvious, because I say things that don't seem to mean much. To not grasp everything, to not understand everything, because mystery looms large in our lives. It is better to get used to it and live with it as soon as possible (s. f. A book that changed my life). 
Solo conociendo el sentido último de las obras tratadas, reflexionando sobre ellas, el mediador podrá limar las diferencias entre el lector adulto y el lector infantil. Es lo que hemos tratado de exponer en el caso de Kitty Crowther.

\section{Referencias Bibliográficas}

\section{Obras de Kitty Crowther}

- (1996). Mon ami Jim. Paris: L'école des Loisirs.

- (2000). Moi et Rien. Paris: L'école des Loisirs.

- (2005). La visite de Petite Mort. Paris: Pastel.

- (2005). iSrcric scrac bibib blub! Barcelona: Corimbo.

- (2007). ¿Entonces? Barcelona: Corimbo.

- (2007). Dans Moi. Editions MeMo.

- (2010). Poka \& Mina. El despertar. Salamanca: Los cuatro azules.

- (2010). Poka \& Mina. En el cine. Salamanca: Los cuatro azules.

- (2011). Theo y Dios. Barcelona: Corimbo.

- (2013). Poka \& Mina. El fútbol. Salamanca: Los cuatro azules.

- (2013). Poka \& Mina. Las alas nuevas. Salamanca: Los cuatro azules.

- (2014). Mère Méduse. Paris: L’école des Loisirs.

- (2015). El niño raíz. Barcelona: Lóguez.

\section{Referencias secundarias}

Bessi, C., (2010). Kitty Crowther: Prix Astrid Lindgren Memorial Award 2010. La Revue des livres pour enfants, 252, p. 139.

Bruner, J. (1988). Realidad mental y mundos posibles. Barcelona: Gedisa.

Chambers, A. (2007). El ambiente de la lectura. México: Fondo de Cultura Económica.

— (2008). Conversaciones. México: Fondo de Cultura Económica.

Cheilan, Liliane, (2010). Silence dehors et dedans, Hors Cadre[s], 6, 26

Colomer, T. (2010). Introducción a la literatura infantil y juvenil actual. Madrid: Síntesis.

- (2005). Andar entre libros. La lectura literaria en la escuela. México: Fondo de Cultura Económica.

Crowther, K. [s. f.]. A book that changed my life. Recuperado de: https://goo.gl/yFSnhO (Consultado el 15/7/ 2016).

- (2013). El álbum es un punto de encuentro entre el niño y el adulto, El Norte de Castilla, 3-7-1013. Recuperado de: https://goo.gl/583sUc (Consultado el 15/7/2016).

Díaz Armas, J. (2008). Lectura literaria y formación inicial. Creencias del profesorado en formación sobre el texto y su lector. En A. Mendoza, y C. Romea, (eds.). 
Textos entre textos. Las conexiones textuales en la formación del lector (pp. 177-190). Barcelona: Horsori.

Dueñas, J. D., Tabernero, R., Calvo, V. y Consejo, E. (2014), La lectura literaria ante nuevos retos: canon y mediación en la trayectoria lectora de futuros profesores. Ocnos, 11, 21-43.

Genette, G. (1987). Seuils. Paris : Éditions du Seuil.

Granado Alonso, C. (2009). Los futuros maestros y maestras ante la educación lectora, Consejería de Cultura de la Junta de Andalucía-Pacto Andaluz por el Libro. En https://goo.gl/qjwTOA (Consultado el 15/7/2016).

Kümmerling-Meibauer, B. (2015). From baby books to picturebooks for adults: European picturebooks in the new millennium. Word \& Image, 31:3, 249-264, DOI:10.1080/02666286.2015.1032519

Larrañaga, E., Yubero, S. y Cerrillo, P. (2008). Estudio sobre los hábitos de lectura de los universitarios españoles. Madrid: CEPLI/SM.

Lluch, G. (2010). Cómo seleccionar libros para niños y jóvenes. Los comités de valoración en las bibliotecas públicas y escolares. Gijón: Trea.

Lluch, G. y Chaparro, J. (2007). La evaluación de los libros para niños y jóvenes. Una investigación sobre la experiencia de Fundalectura, Ocnos, 3, 103-109.

Lorraine, W. (2012). El significado de la ilustración en los libros para niños. Entrevista con Maurice Sendak, Imaginaria, 314, mayo 2012 [reed. del texto publicado en Parapara, ejemplar editado por el Banco del Libro (Sección Venezolana de IBBY), el Proyecto Interamericano de Literatura Infantil (PILI) y el Instituto Autónomo Biblioteca Nacional de Venezuela (Caracas, junio de 1980)]. Recuperado de: https://goo.gl/gEhEjy (Consultado el 17/10/2016).

Los cuatro azules. Ediciones y publicaciones de libros infantiles. Recuperado de: https://goo.gl/Nmj5C5 (Consultado el 17/10/2016).

Mendoza, A. (2004). La educación literaria. Bases para la formación de la competencia lecto-literaria. Málaga: Aljibe.

Mirandola, G. (2010). Dans moi. Entretien avec Kitty Crowther. Hors Cadre[s], 6, 29.

Munita, F. (2013). Creencias y saberes de futuros maestros (lectores y no lectores) en torno a la educación literaria. Ocnos, 9, 69-87. Recuperado en https://goo.gl/dMJc2R (Consultado el 15/7/2016).

- (2014). El mediador escolar de lectura literaria. (Tesis doctoral recuperada en https://goo.gl/KZ5VQw (Consultado el 15/7/2015).

Nikolajeva, M. (2014). Retórica del personaje en la literatura para niños. México: Fondo de Cultura Económica.

Nodelman, P. (2008). The Hidden Adult. Baltimore: Johns Hopkins University Press. 
- (2010). Las narrativas de los libros-álbum y el proyecto de la literatura infantil. En T. Colomer, B. Kümerling-meibauer y C. Silva-Díaz (Eds.). Cruce de miradas: Nuevas aproximaciones al libro-álbum (pp. 18-32). Barcelona: Banco del LibroGretel.Picturebook Makers, (2015). Recuperado de: https://goo.gl/5ceP4k (Consultado el 15///2016).

Posas A. (2010). Kitty Crowther: los niños no son asustadizos. Recuperado de: https://goo.gl/YKhpkf (Consultado el 15/7/ 2015).

Rosenblatt, L. (2002). La literatura como exploración. México: Fondo de Cultura Económica.

Salisbury, M. (2005). La ilustración de libros infantiles. Barcelona: Acanto.

— (2014). 100 joyas de la literatura infantil ilustrada. Barcelona: Blume.

Salisbury, M. \& Styles, M. (2012). El arte de ilustrar libros infantiles. Barcelona: Blume.

Silva-Díaz, C. (2001), La formación de los maestros en literatura infantil: un estudio diagnóstico (primera y segunda parte). Cuatrogatos: Revista de literatura infantil, 5 y 6. Recuperado de: https://goo.gl/uPxev4(Consultado el 15/7/ 2015).

Sipe, L. (2000). The Construction of Literary Understanding by First and Second Graders in Oral Response to Picture Storybook Read-Alouds, Reading Research Quarterly, 35 (2), 252-275.

- (2010). Conferencia. Cómo responden los niños a los álbumes ilustrados: Cinco tipos de comprensión lectora. Universidad de Pensilvania.

Soriano, M. (2001). La literatura para niños y jóvenes. Buenos Aires: Colihue.

Styles, M. \& Arizpe, E. (2004). Lectura de imágenes. México: Fondo de Cultura Económica.

Tabernero Sala, R. (2013). El lector literario en los grados de maestro. Deconstruir para construir, Lenguaje y Textos, 38, 47-56.

- (2014). El discurso literario infantil en el desarrollo de la competencia literaria: claves para seleccionar libros infantiles, Aula de Innovación educativa, 228, 3539.

— (2015). “¿De qué sirve un libro sin dibujos...?.” Álbum y formación de lectores literarios. Aula de Innovación educativa, 239, 28-32.

Thiry, A.-S. (2006). Kitty Crowther, et alors?. https://goo.gl/O7Rzx4. (Consultado el 15/7/ 2015).

Van Der Linden, S. (2006). Lire l'album. Le Puy-en-Vela: L'atelier du poisson soluble.

- (2008). Du plein au vide. Hors cadre [s], 2, 18-21. 
- (2010). Rêver est-il jouer? De la chambre à l'imaginaire, aller et retour. Hors cadre [s], 6, 12-15.

— (2013a). Album[s]. Arles: Éditions de Facto.

- (2013b). Pequeñas narraciones naturales a través de un hilo. Fuera de margen, 12, 20-23.

Zugasti, Ana, (2015). El mundo de Kitty Crowther. Recuperado de: https://goo.gl/zW2Hxi. (Consultado el 15/7/ 2015). 